\title{
Effect of smoking cessation on tooth loss: a systematic review with meta-analysis
}

\author{
Maria Luisa Silveira Souto ${ }^{1}$ Emanuel Silva Rovai ${ }^{1,2}$, Cristina Cunha Villarr, Mariana Minatel Braga ${ }^{3}$ and \\ Cláudio Mendes Pannuti ${ }^{1 *}$
}

\begin{abstract}
Background: Smoking is a major risk factor for periodontitis and tooth loss. Smoking cessation has a positive impact in periodontal treatment. However, so far, no systematic review has evaluated the effect of smoking cessation on tooth loss. Therefore, this review aimed to evaluate if smoking cessation reduces the risk of tooth loss.

Methods: Observational (cross-sectional and longitudinal) studies that investigated the association between smoking cessation and tooth loss were included. MEDLINE, EMBASE and LILACS databases were searched for articles published up to November 2018. Pooled results for subgroups of current and former smokers were compared in meta-analysis. Meta-regression was used to test the influence of smoking status on estimates and explore the heterogeneity.

Results: Of 230 potentially relevant publications, 21 studies were included in the qualitative review and 12 in the quantitative analysis. Meta-analysis of cross-sectional studies did not show any differences between former and current smokers in the chance of losing 1 or more teeth $\left(\mathrm{OR}=1.00 ; 95 \% \mathrm{Cl}=0.80\right.$ to $\left.1.24, \mathrm{I}^{2}=80 \%\right)$, losing more than 8 teeth $\left(\mathrm{OR}=1.02 ; 95 \% \mathrm{Cl}=0.78\right.$ to $\left.1.32, \mathrm{I}^{2}=0 \%\right)$ or being edentulous $\left(\mathrm{OR}=1.37 ; 95 \% \mathrm{Cl}=0.94\right.$ to $1.99, \mathrm{I}^{2}=$ 98\%). Meta-analysis from longitudinal studies showed that, when compared to never smokers, former smokers presented no increased risk of tooth loss ( $R R=1.15 ; 95 \% \mathrm{Cl}=0.98$ to $\left.1.35, \mathrm{I}^{2}=76 \%\right)$, while current smokers presented an increased risk of tooth loss ( $R R=2.60 ; 95 \% \mathrm{Cl}=2.29$ to $\left.2.96, \mathrm{I}^{2}=61 \%\right)$. Meta-regression showed that, among former smokers, the time of cessation was the variable that better explained heterogeneity (approximately $60 \%)$.
\end{abstract}

Conclusions: Risk for tooth loss in former smokers is comparable to that of never smokers. Moreover, former smokers have a reduced risk of tooth loss, when compared to current smokers.

Keywords: Tobacco, Cigarette smoking, Tobacco use cessation, smoking cessation, Tooth loss, periodontitis, Metaanalysis

\section{Background}

Cumulative evidence from cross-sectional and cohort studies supports a causal relationship between cigarette smoking and the initiation and progression of periodontitis [1-5]. Smokers present greater extent and severity of periodontitis [6, 7]. Conversely, smoking cessation has a positive impact in the outcomes of non-surgical periodontal therapy [8-12].

\footnotetext{
*Correspondence: pannuti@usp.br

${ }^{1}$ Division of Periodontics, University of São Paulo, School of Dentistry, Av.

Prof. Lineu Prestes, 2227, São Paulo, SP 05508-000, Brazil

Full list of author information is available at the end of the article
}

Tooth loss is the final outcome of periodontal disease. It is associated with loss of masticatory function [13], lack of self-esteem and impaired social interactions due to limited aesthetic appearance [14, 15]. Consequently, tooth loss has a negative impact on oral health-related quality of life [16]. Smokers are more likely to lose their teeth than non-smokers $[17,18]$, as a result of their increased severity of periodontitis. Cross-sectional $[19,20]$ and prospective studies $[21,22]$ have also suggested that former smokers have a significantly lower risk of tooth loss than current smokers.

Previous reviews have addressed the association between smoking and tooth loss $[17,18]$. However, so far,

(c) The Author(s). 2019 Open Access This article is distributed under the terms of the Creative Commons Attribution 4.0 International License (http://creativecommons.org/licenses/by/4.0/), which permits unrestricted use, distribution, and reproduction in any medium, provided you give appropriate credit to the original author(s) and the source, provide a link to the Creative Commons license, and indicate if changes were made. The Creative Commons Public Domain Dedication waiver (http://creativecommons.org/publicdomain/zero/1.0/) applies to the data made available in this article, unless otherwise stated. 
no review has focused on the effect of smoking cessation on tooth loss. Further, there is no meta-estimate to quantify the impact of smoking cessation on tooth loss. Therefore, the aim of this systematic review was to answer the following focused question: "Does smoking cessation reduce the risk of tooth loss in former smokers, when compared to current smokers?"

\section{Methods}

This review has been prepared according to the Preferred Reporting Items for Systematic Reviews and Meta-Analyses (PRISMA) guidelines [23] and Metaanalysis of Observational Studies in Epidemiology (MOOSE) guidelines [24]. The protocol was registered in the International Prospective Register of Systematic Reviews - PROSPERO (CRD42018085095).

\section{Eligibility criteria}

Only observational studies (cross-sectional and longitudinal studies) were included in this systematic review because, for ethical reasons, there are no randomized clinical trials with a control group that did not receive smoking cessation therapy. The inclusion criteria were as follows: a) original studies published in English; b) data comparing former smokers with current smokers and never smokers; c) studies that had tooth loss as an outcome.

We excluded narrative reviews, case series, case reports, in vitro and animal studies. Further, we excluded studies that did not include former smokers in the analysis, or that combined former smokers with never smokers or current smokers, or that did not associate smoking with tooth loss (e.g., smoking was used only for adjustment).

\section{Search strategy}

An electronic literature search was conducted in the following databases: MEDLINE (PubMed), Web of Science and Cochrane Library in September 2019. The following search strategy was used: $(((()((($ epidemiology) OR observational study) OR longitudinal) OR cohort) OR cross-sectional) OR prospective) OR retrospective)) AND $(((((($ tooth) OR tooth [MeSH Terms] $)$ OR tooth loss) OR tooth survival) OR periodontitis) OR periodontal disease) OR Periodontal Diseases [MeSH Terms])) AND $(((()(($ tobacco) $)$ OR Tobacco Use Disorder [MeSH Terms]) OR cigarette smoking) OR tobacco products) OR smoking cessation) OR smoking [MeSH Terms]) OR smoking cessation [MeSH Terms]) OR tobacco use cessation)). We also conducted a hand search of references lists from included publications.

In the first phase, two reviewers (MLSS and ESR) screened independently titles and abstracts identified by the search strategy. Disagreements were resolved by discussion or, if necessary, by the decision of a third reviewer (CMP). In the second phase, the same reviewers screened full texts of the studies that met inclusion criteria, or those with unclear information in the title and abstract. Reasons for rejection of studies were recorded for each report.

\section{Data extraction}

The following items were extracted from the publications that met inclusion criteria: author, year, country, study design, sample size, measures of exposure (smoking status), measures of outcome (tooth loss), results, conclusions, conflict of interest and source of funding. Authors of the included studies were contacted for missing, relevant data.

\section{Risk of bias}

Risk of bias of cohort studies was assessed using a modified version of the Newcastle-Ottawa scale (NOS) [25]. For cross-sectional studies, we adapted the Modesti et al. (2016) version of the NOS scale [26].

The NOS for cohort studies comprised 10 questions about selection of the study groups (i.e. representativeness of current and former smokers), comparability of the groups, outcome (criteria used to assess tooth loss and adequacy of follow-up) and statistical analysis. The scores ranged from 0 to 11 . Studies with 9-11 stars were arbitrarily rated as low risk of bias, $6-8$ stars moderate risk of bias and $<6$ high risk of bias.

The NOS for cross-sectional studies comprised 07 questions about selection of the study groups (i.e. representativeness of the sample), comparability of the groups, outcome (criteria used to assess tooth loss) and statistical analysis. The scores ranged from 0 to 10 . Studies with 7-10 stars were arbitrarily rated as low risk of bias, 5-6 stars moderate risk of bias and $<5$ high risk of bias.

\section{Summary measures and synthesis of results}

Analyses of data extracted from cross-sectional studies were carried out using software Review Manager (RevMan) (Version 5.3. Copenhagen: The Nordic Cochrane Centre, The Cochrane Collaboration, 2014). Randomeffects meta-analyses were conducted for the following outcomes: loss of one or more teeth, loss of more than eight teeth and being edentulous. The estimates were presented as pooled odds radios (ORs) and their respective 95\% confidence intervals (CIs). Heterogeneity was tested using the Cochran's Q test and quantified using the I-square test (level of inconsistency) and $\mathrm{Tau}^{2}$ (estimate of between-study variance).

Meta-analyses were performed to assess the risk of tooth loss among subgroups of former and current smokers, compared to the control group (never 
smokers). OR values for studied groups (former and current smokers) were converted into LogOR and results from individual studies were pooled using a randomeffects model. Former and current smokers were considered as different subgroups and contrasted with never smokers. Differences between subgroups (subsets) were also tested based on random-effects models. Metaanalysis used the inverse variance method and the DerSimonian-Laird estimator for $\mathrm{Tau}^{2}$. The pooled results were estimated using the Risk Ratio (RR), Relative Risk and 95\% CIs. Heterogeneity was tested similarly to the cross-sectional studies.

Meta-regressions were used to test the influence of different moderators (age, time of cessation and dropout rates) on pooled estimates. After testing each variable in the model, residual heterogeneity $\left(\mathrm{I}^{2}\right)$ and amount of heterogeneity accounted for each variable $\left(R^{2}\right)$ could be calculated. Funnel plot visual analysis and linear regression test of funnel plot asymmetry were used to assess publication bias of the longitudinal studies. Both metaregressions and publication bias investigation were performed considering subgroups separately.

Data analyses of longitudinal studies were performed using the "meta" and "metafor" packages, $\mathrm{R}$ software ( $\mathrm{R}$ Studio, Version 1.0.143).

\section{Results}

\section{Search results and excluded trials}

From a total of 2160 papers identified from electronic databases and hand searching, 2131 were excluded after review of titles or abstract. In the second phase, 29 papers $[3,5,19-22,27-49]$ were read in full. After evaluation of the full report, eight [5, 30, 44-49] were excluded. At the end, 21 publications [3, 19-22, 27-29, 31-43] were included in this review. Of these, 12 [20, $27,28,31,33-35,38,40-43]$ presented data that could be analyzed in meta-analysis (Flowchart- Fig. 1). Only observational studies (cross-sectional and longitudinal studies) were included because there was no randomized clinical study with tooth loss as outcome.

\section{Included studies}

\section{Cross-sectional studies}

Fourteen cross-sectional studies were included in this review [19, 20, 27-29, 31-39]. Their characteristics are depicted in Table 1. A total of 567,491 individuals from both sexes, ranging 18-99 years were included.

For smoking status assessment, self-administered questionnaires $[20,27,31,36-39]$ and interviews [19, $28,29,32-35]$ were performed. In respect of outcome assessment, tooth loss was determined by clinical examination in ten studies [19, 20, 29, 31-34, 37-39], self-reported questionnaire in three $[27,35,36]$ and telephone interview in one [28].

\section{Longitudinal studies}

Among the 21 included studies, seven [3, 21, 22, 40-43] were longitudinal studies. Their characteristics are shown in Table 2. In total, 70,898 individuals were followed for a period that ranged from 4 to 35 years. Three studies [21, 22, 43] included just males subjects and the other four [3, 40-42] included both males and females.

Smoking behavior was determined using self-reported questionnaires [22, 40, 42, 43] or interviews [3, 21, 41], whereas tooth loss was assessed by clinical examination $[3,21,43]$, self-reported questionnaires $[22,40,42]$ or interviews [41].

\section{Methodological quality of included studies Cross-sectional studies}

Risk of bias assessment of the cross-sectional studies was evaluated according to the NOS domains (Table 3). Of the 14 cross-sectional studies included, five $(35.7 \%)$ were considered to have low risk of bias [28, 29, 33-35], seven (50\%) presented moderate risk $[19,20,27,31,36-38]$ and two $(14.3 \%)[32,39]$ were judged to have high risk of bias.

\section{Longitudinal studies}

Risk of bias of the longitudinal studies is shown in Table 4. None of the included studies were considered to have high risk of bias. Most of the studies [21, 22, 40-43] were considered to have moderate risk of bias and just one study [3] presented a low risk of bias.

\section{Pooled outcomes}

\section{Cross-sectional studies}

Concerning cross-sectional studies, a total of three meta-analyses comparing former vs current smokers were conducted. Former smokers were compared to current smokers as regards number of: (i) edentulous subjects, (ii) patients who lost 1 or more teeth and (iii) patients who lost more than 8 teeth. Pooled estimates comparing former vs current smokers showed no significant difference in the odds of being edentulous $(\mathrm{OR}=1.37 ; 95 \% \mathrm{CI}=0.94$ to 1.99 , Heterogeneity: $\left.\mathrm{I}^{2}=98 \%, p=0.10\right)$, losing 1 or more teeth $(\mathrm{OR}=1.00$; $95 \% \mathrm{CI}=0.80$ to 1.24 , Heterogeneity: $\mathrm{I}^{2}=80 \%, p=$ $0.97)$ and losing more than 8 teeth $(\mathrm{OR}=1.02$; $95 \%$ $\mathrm{CI}=0.78$ to 1.32 , Heterogeneity: $\mathrm{I}^{2}=0 \%, p=0.89$ ). (Figs. 2, 3 and 4).

\section{Longitudinal studies}

The risk of tooth loss among those who quit smoking was not significantly different from never smokers. Contrarily, current smokers presented a risk of tooth loss twice higher than never smokers. Moderate to high level 


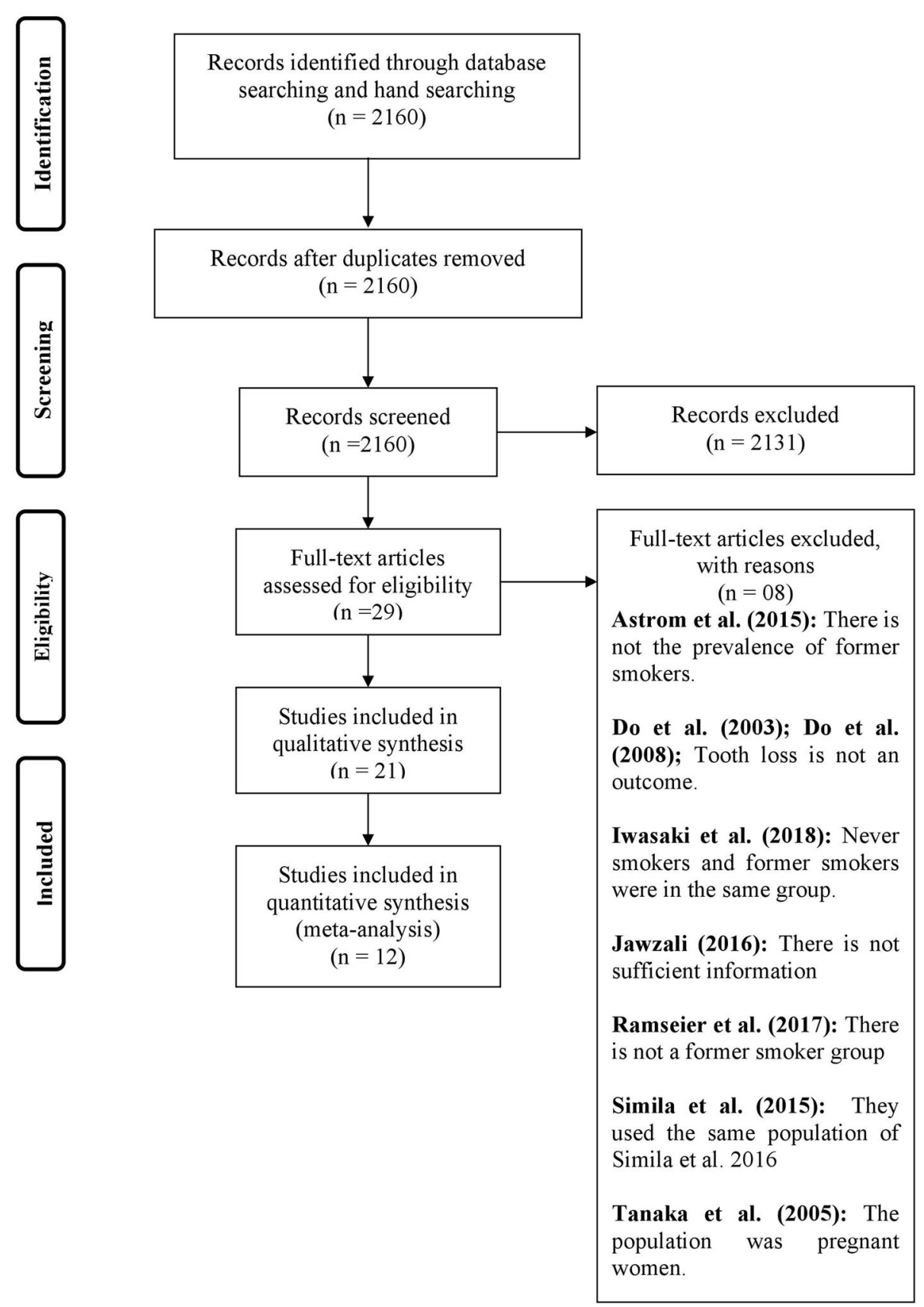

Fig. 1 Flow-chart of studies screened, retrieved, included and analyzed in the systematic review and subsequent meta-analyses

of heterogeneity was found even within the subgroups (Fig. 5).

Among former smokers, the time of cessation was the variable that explained a considerable part of the heterogeneity (around 60\%), resulting in a low residual heterogeneity (around 20\%) when included in the regression model (Table 5). However, the level of significance was not inferior to $5 \%$. On the other hand, for current smokers, no moderator was significantly associated with the estimates (Table 5). The funnel plots showed no visual or statistically tested asymmetries (Additional file $1 \mathrm{a}$ and $\mathrm{b}$ ).

\section{Discussion}

The aim of this systematic review was to assess if smoking cessation reduces the risk of tooth loss in former smokers, when compared to current smokers. Our results showed that smoking cessation may reduce the risk of tooth loss. Meta-analysis of data from longitudinal studies showed that the rate of tooth loss in former 


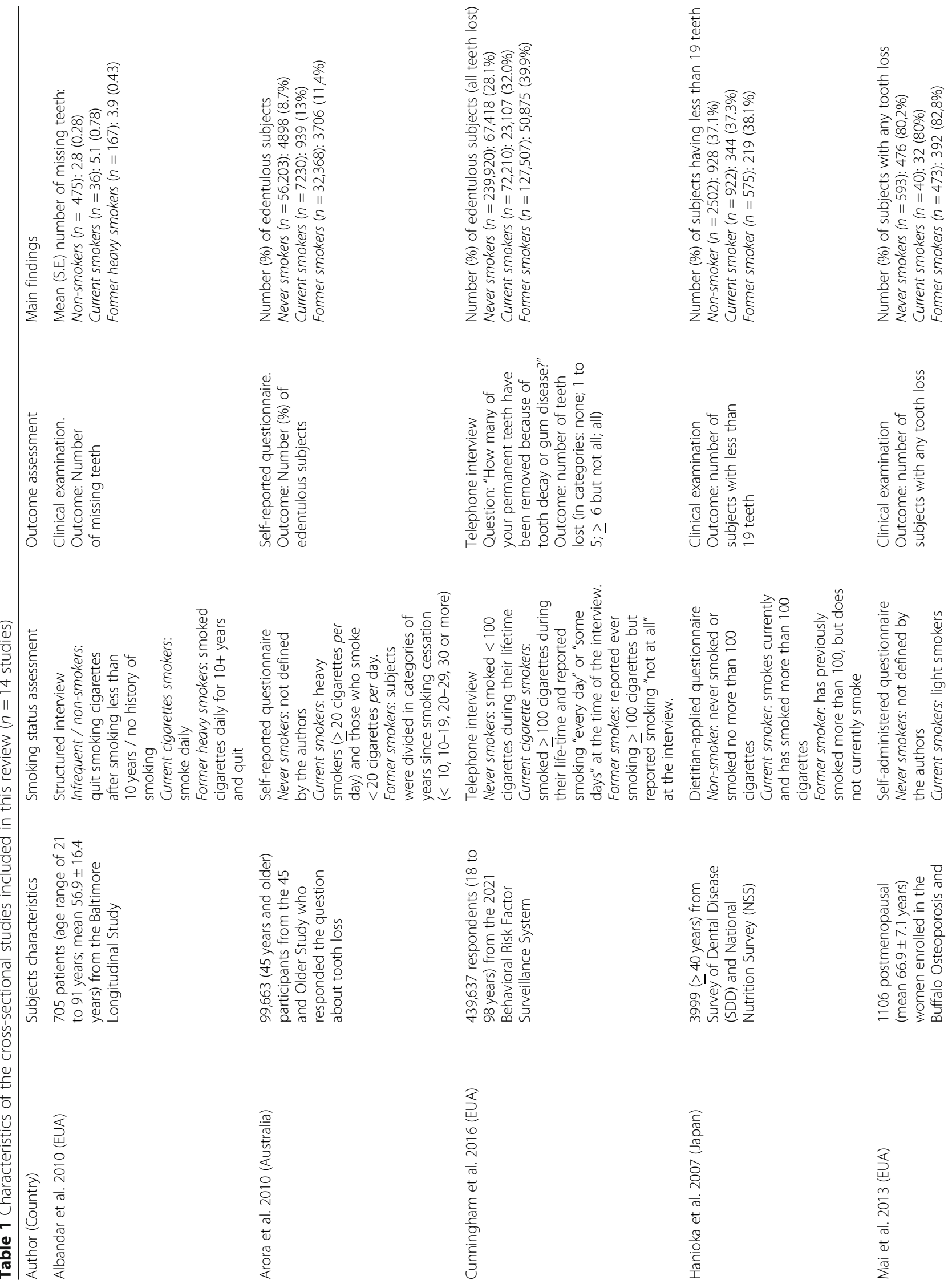



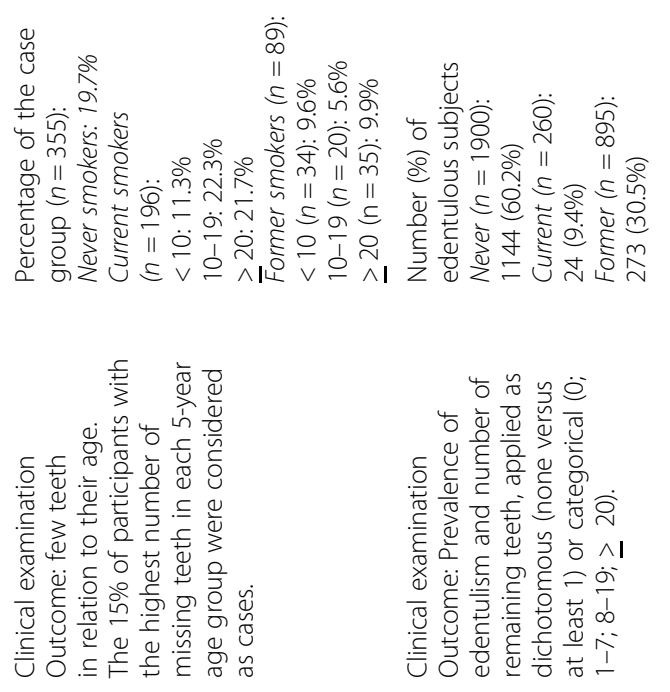

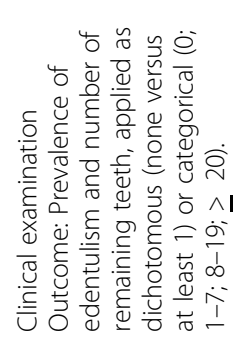

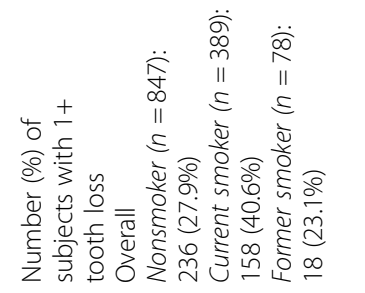
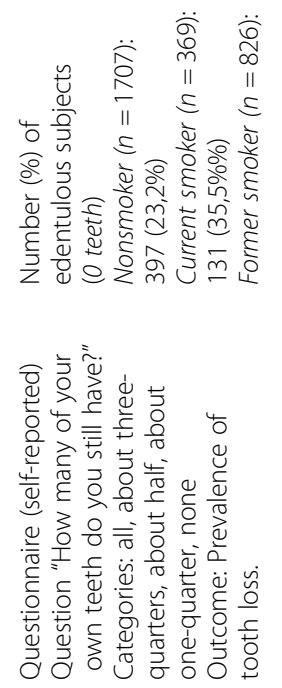

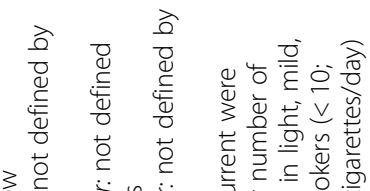

उ

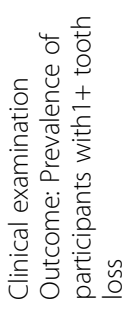

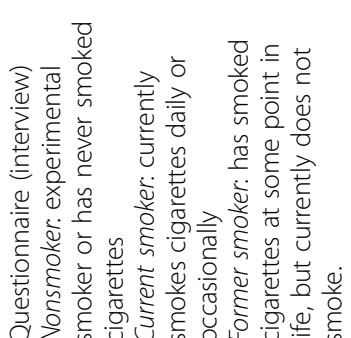

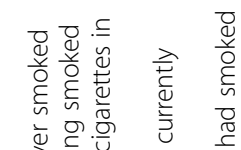
远

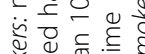

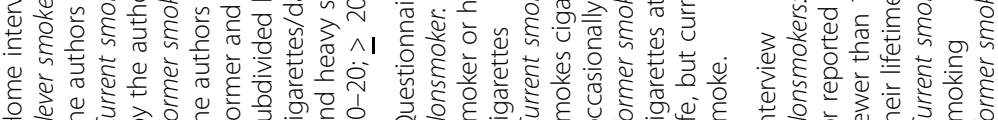

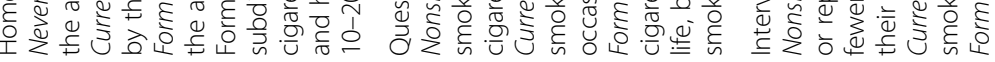

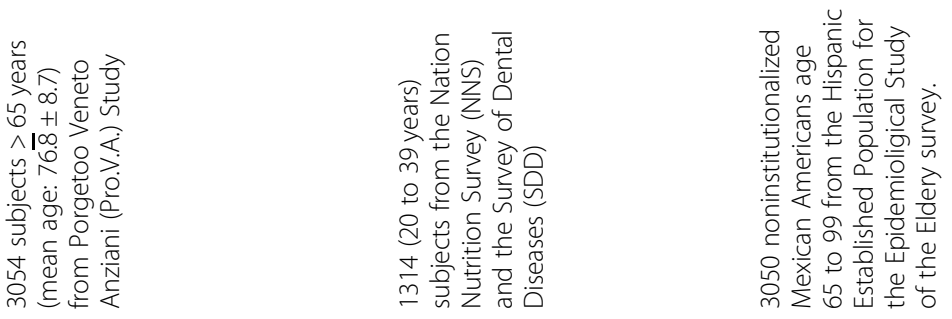



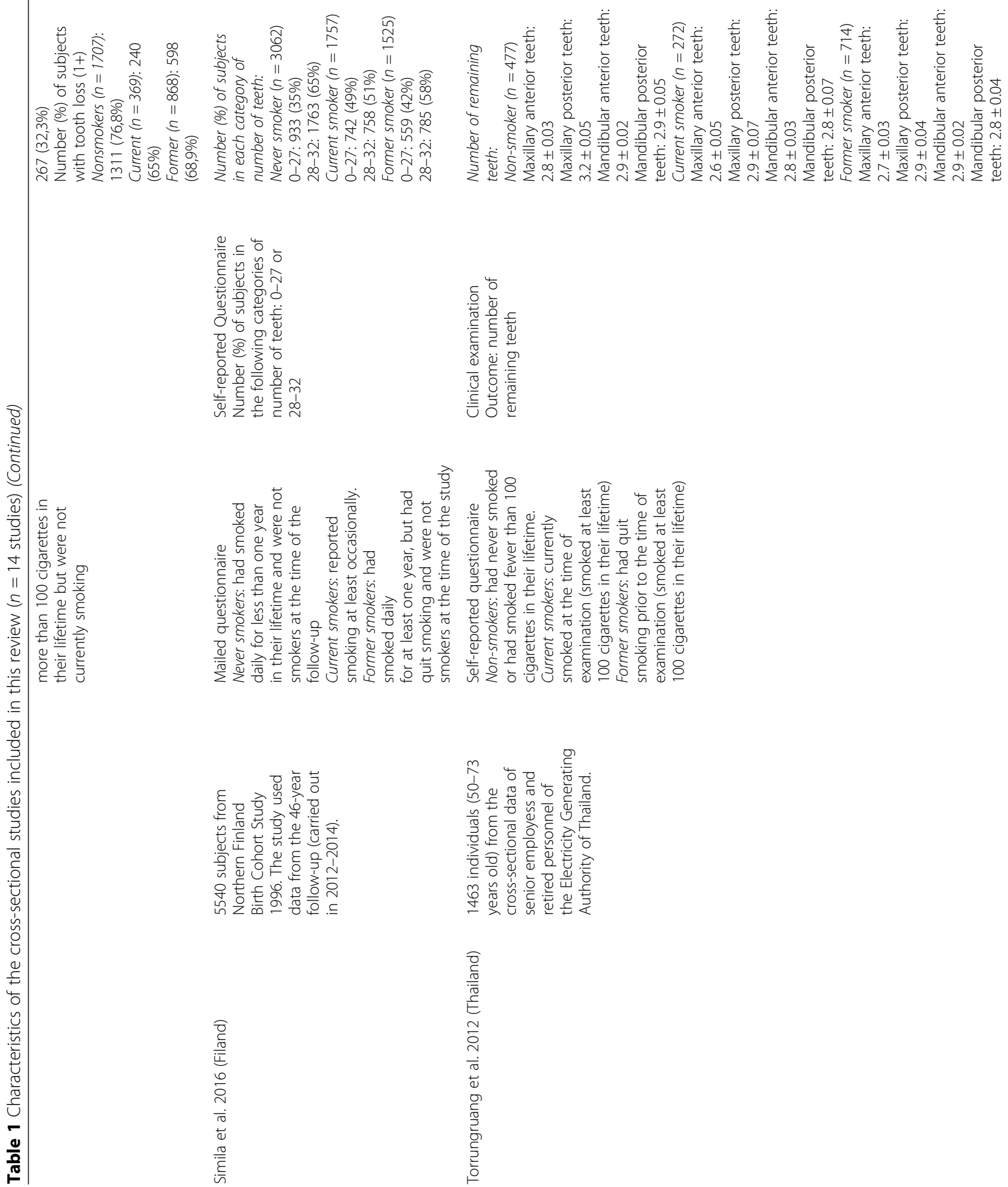

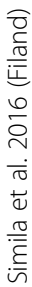

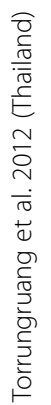




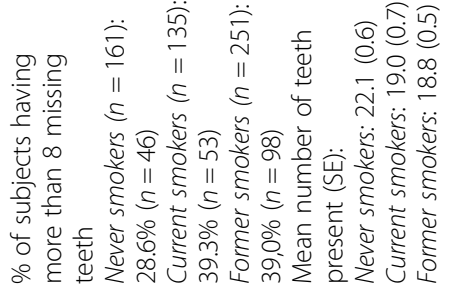

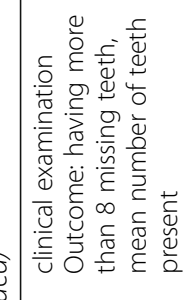

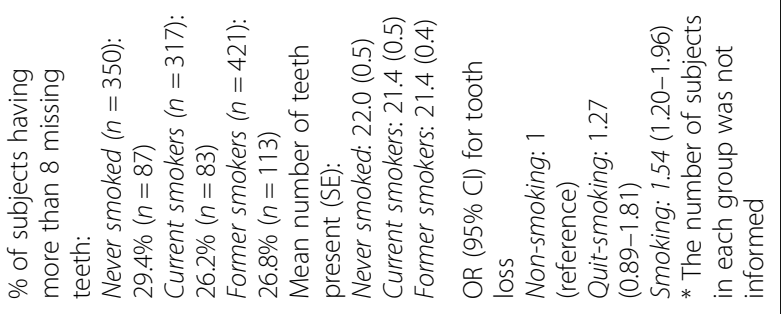

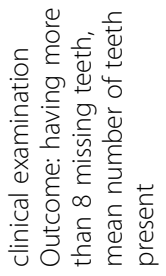

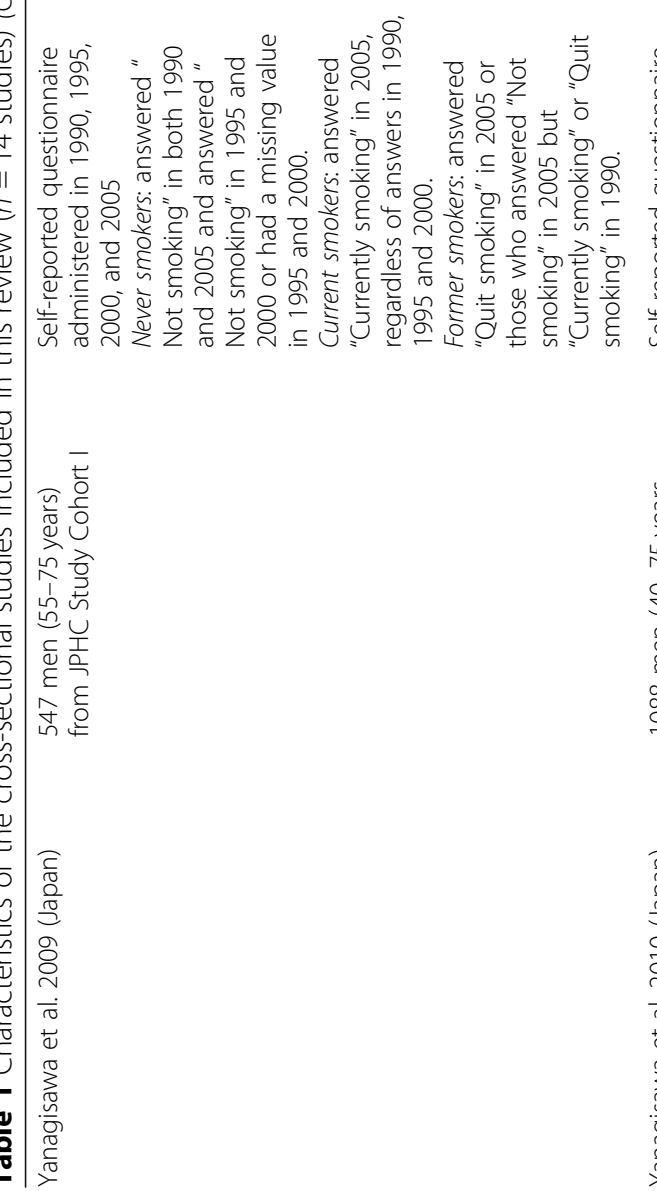
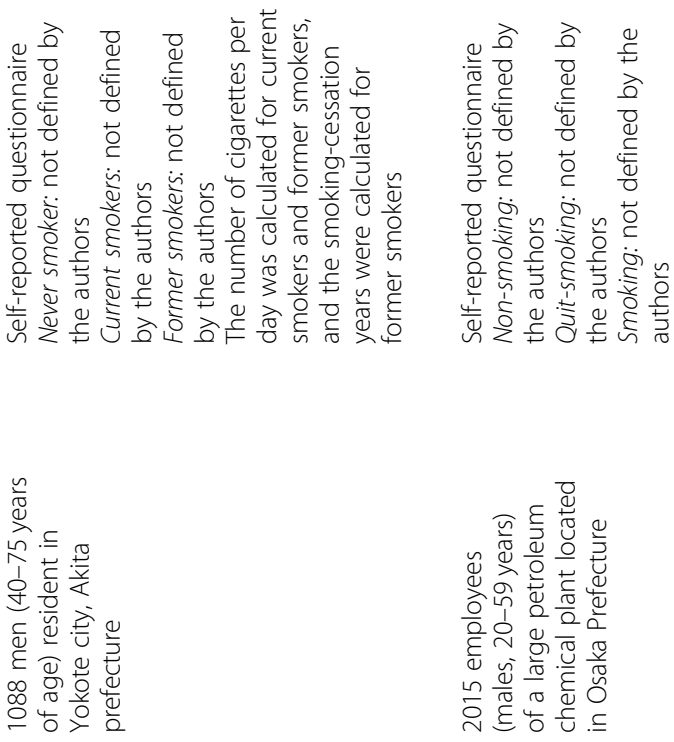

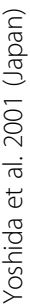

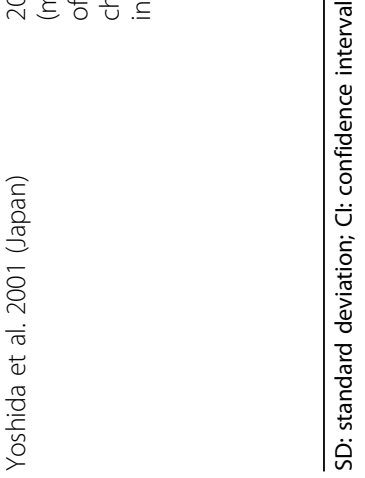




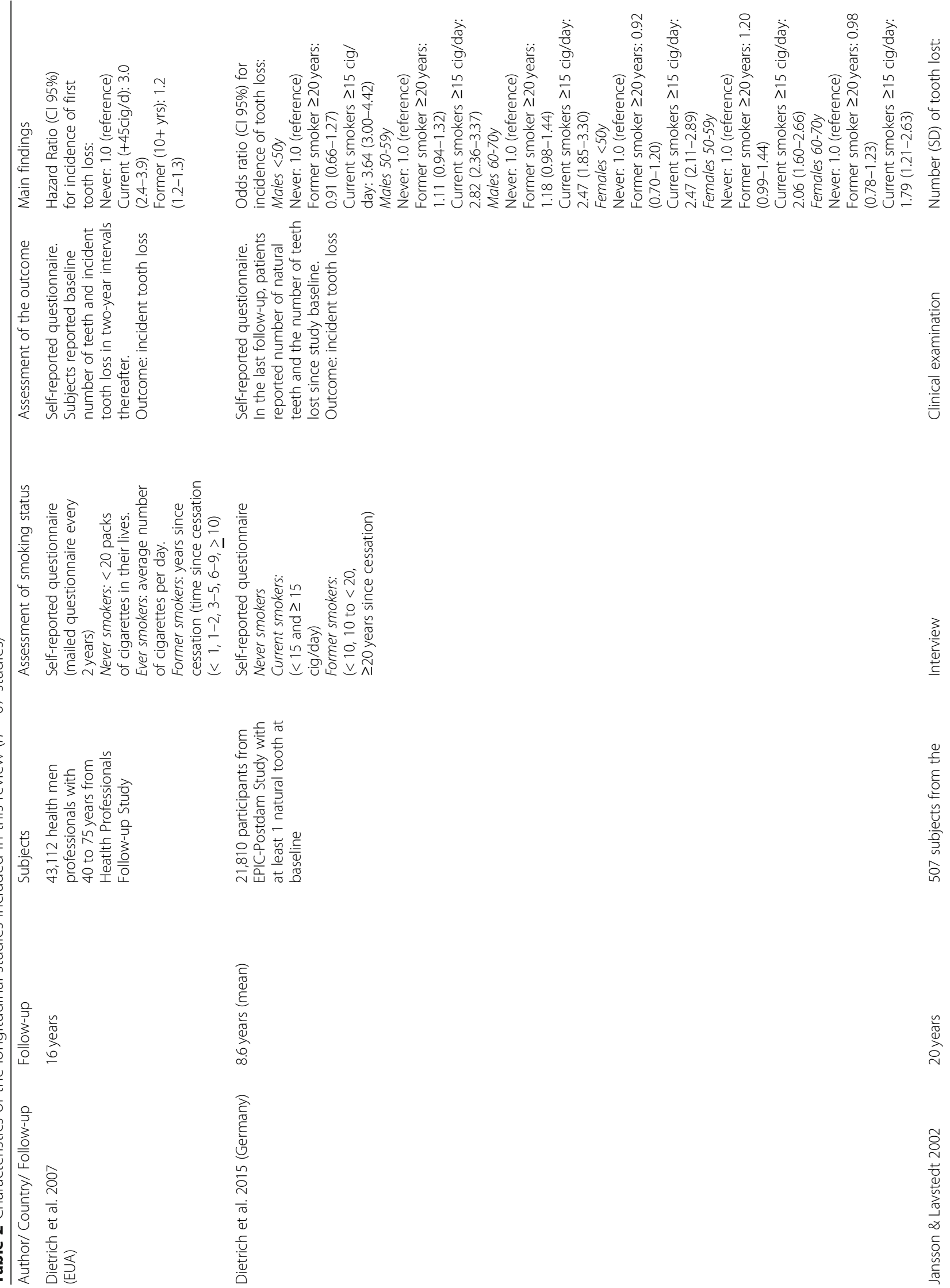




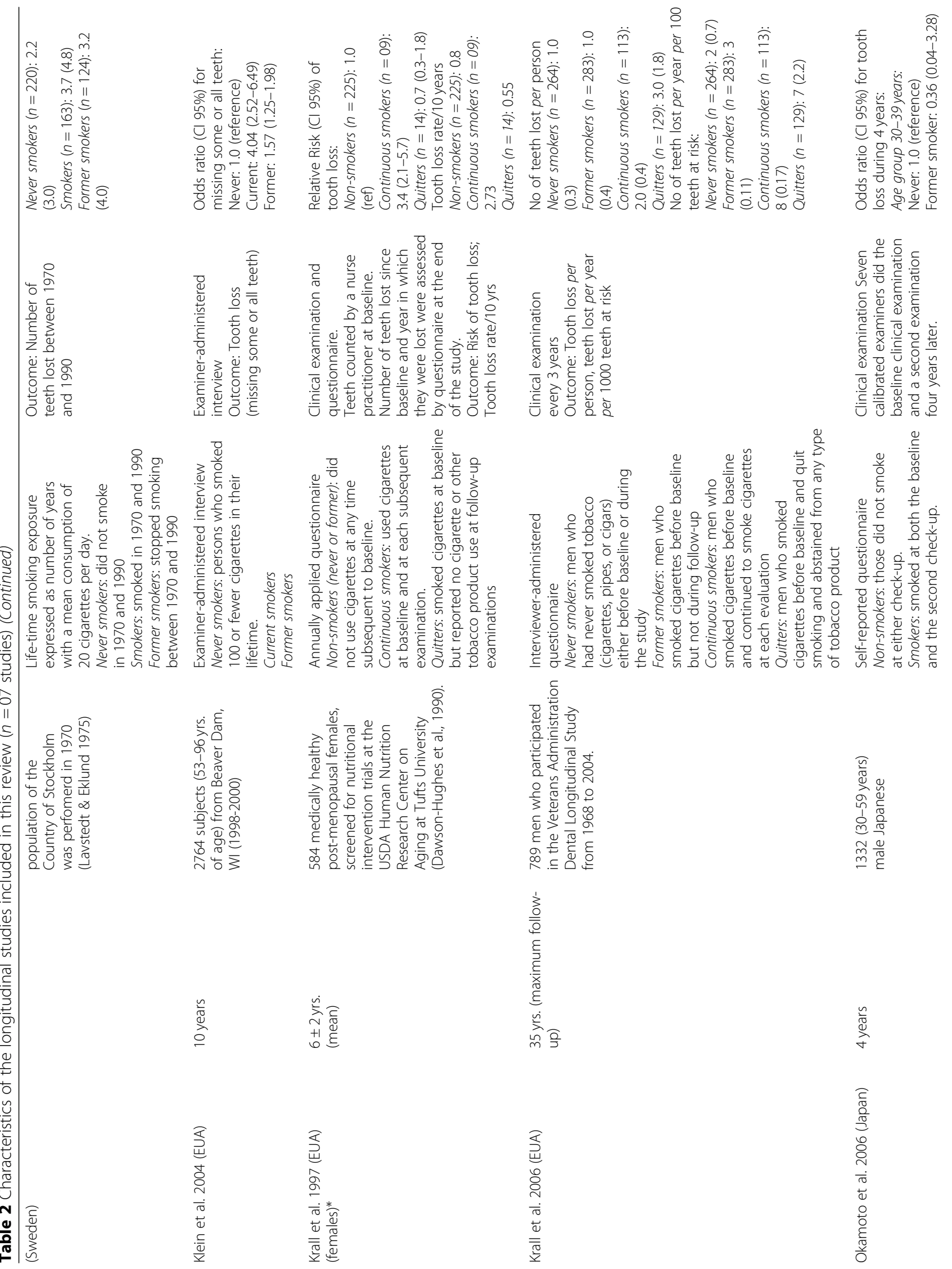




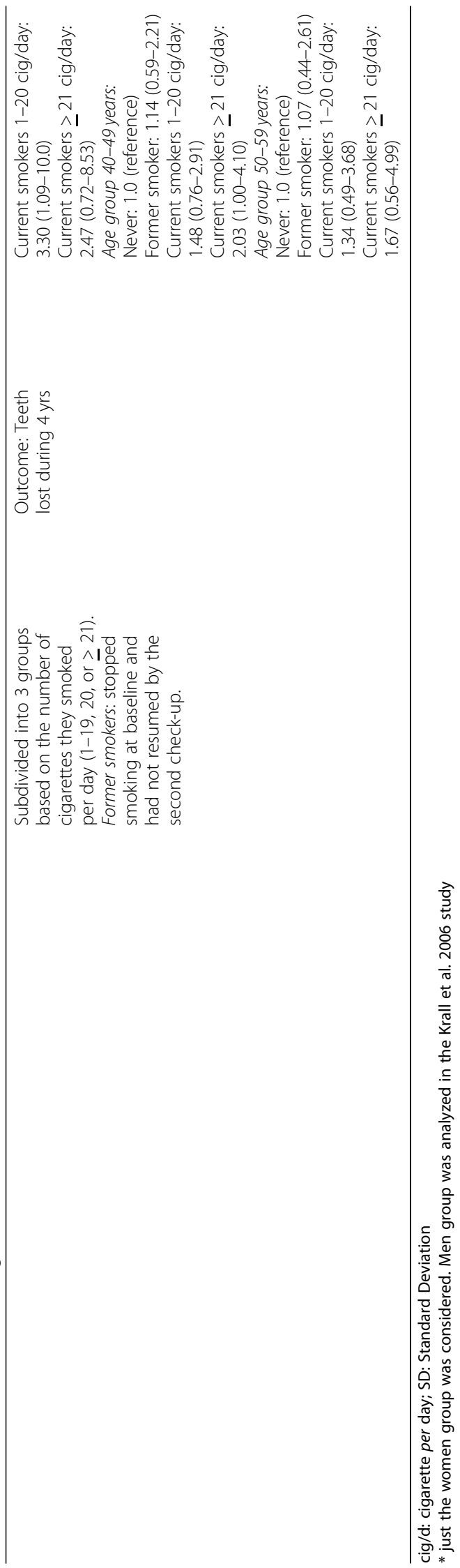


Table 3 Risk of bias assessment of included cross-sectional studies

\begin{tabular}{|c|c|c|c|c|}
\hline & $\begin{array}{l}\text { Selection } \\
\text { (maximum 5) }\end{array}$ & $\begin{array}{l}\text { Comparability } \\
\text { (maximum 2) }\end{array}$ & $\begin{array}{l}\text { Outcome } \\
\text { (maximum 3) }\end{array}$ & $\begin{array}{l}\text { Total } \\
\text { (maximum 10) }\end{array}$ \\
\hline Albandar et al. 2010 & $1 \star$ & $1 \star$ & $3 \star$ & $5 \star$ \\
\hline Arora et al. 2010 & $3 \star$ & $1 \star$ & $1 \star$ & $5 \star$ \\
\hline Cunningham et al. 2016 & $4 \star$ & $2 \star$ & $1 \star$ & $7 \star$ \\
\hline Hanioka et al. 2007 & $3 \star$ & $1 \star$ & $3 \star$ & $7 \star$ \\
\hline Mai et al. 2013 & $1 \star$ & $2 \star$ & $3 \star$ & $6 \star$ \\
\hline Mundt et al. 2007 & $3 \star$ & $1 \star$ & $3 \star$ & $3 \star$ \\
\hline Musacchio et al. 2007 & $3 \star$ & $1 \star$ & $3 \star$ & $7 \star$ \\
\hline Ojima et al. 2007 & $3 \star$ & $1 \star$ & $3 \star$ & $7 \star$ \\
\hline Randolph et al. 2001 & $4 \star$ & $2 \star$ & $1 \star$ & $7 \star$ \\
\hline Simila et al. 2006 & $2 \star$ & $2 \star$ & $1 \star$ & $5 \star$ \\
\hline Torrungruang et al. 2012 & $0 \star$ & $2 \star$ & $3 \star$ & $5 \star$ \\
\hline Yanagisawa et al. 2009 & $1 \star$ & $1 \star$ & $3 \star$ & $5 \star$ \\
\hline Yanagisawa et al. 2010 & $2 \star$ & $1 \star$ & $3 \star$ & $6 \star$ \\
\hline Yoshida et al. 2001 & $0 \star$ & $1 \star$ & $3 \star$ & $4 \star$ \\
\hline
\end{tabular}

Scores ranged from 0 to 10 stars. Studies with 7-10 stars were arbitrarily rated as low risk of bias, 5-6 stars moderate risk of bias and $<5$ high risk of bias

smokers is similar to that of never smokers. Moreover, current smokers had a risk of tooth loss twice higher than never smokers. These results are consistent with a previous systematic review that found a causal relationship between smoking and tooth loss and a decreased risk of tooth loss in former smokers [17]. However, the effect of smoking cessation on tooth loss had not been explored in this previous review. To the best of the authors' knowledge, this is the first systematic review with meta-analysis that included never, former and current smokers, as different levels of exposures to smoking and investigated their association to tooth loss.

The most plausible biological explanation for the increased risk of tooth loss in smokers is the destruction of the periodontal supporting tissues [17]. A recent systematic review showed that the risk for periodontitis incidence and progression could be reversed after smoking cessation to the same level as that of never smokers [12]. These results are in agreement with our findings that the risk of tooth loss between former smokers and never smokers were not significantly different.

In contrast to the results from longitudinal studies, the meta-analysis of data from cross-sectional studies did not show significant differences between former smokers and current smokers in relation to the risk of being edentulous, losing one or more teeth and losing eight or more teeth. The possible reason for this lack of effect is the inherent limitations of cross-sectional studies, especially the absence of information about the temporal relationship between cause (smoking cessation) and effect (tooth loss). For example, none of the included crosssectional studies assessed the time of tooth loss. Thus, it is possible that former smokers lost their teeth before stopped smoking. Moreover, most of these studies failed to report the non-smoking duration for subjects that ceased the habit. It is possible that many quitters in the included studies have stopped smoking for less than 5 years. Considering that it may take at least 10 to 20 years of abstinence for the risk to return to the level of never

Table 4 Methodological quality of the longitudinal studies

\begin{tabular}{|c|c|c|c|c|c|}
\hline & $\begin{array}{l}\text { Selection } \\
\text { (maximum 4) }\end{array}$ & $\begin{array}{l}\text { Comparability } \\
\text { (maximum 2) }\end{array}$ & $\begin{array}{l}\text { Outcome } \\
\text { (maximum 3) }\end{array}$ & $\begin{array}{l}\text { Statistics } \\
\text { (maximum 2) }\end{array}$ & $\begin{array}{l}\text { Total } \\
\text { (maximum 11) }\end{array}$ \\
\hline Dietrich et al. 2007 & $2 \star$ & $2 \star$ & $2 \star$ & $2 \star$ & $8 \star$ \\
\hline Dietrich et al. 2015 & $2 \star$ & $2 \star$ & $2 \star$ & $2 \star$ & $8 \star$ \\
\hline Jansson \& Laystedt. 2002 & $4 \star$ & $1 \star$ & $2 \star$ & $2 \star$ & $9 \star$ \\
\hline Klein et al. 2004 & $3 \star$ & $1 \star$ & $1 \star$ & $1 \star$ & $6 \star$ \\
\hline Krall et al. 1997 & $3 \star$ & $0 \star$ & $1 \star$ & $2 \star$ & $6 \star$ \\
\hline Krall et al. 2006 & $3 \star$ & $1 \star$ & $2 \star$ & $2 \star$ & $8 \star$ \\
\hline Okamoto et al. 2006 & $1 \star$ & $1 \star$ & $2 \star$ & $2 \star$ & $6 \star$ \\
\hline
\end{tabular}

Scores ranged from 0 to 11 stars. Studies with 9-11 stars were arbitrarily rated as low risk of bias, 6-8 stars moderate risk of bias and $<6$ high risk of bias 


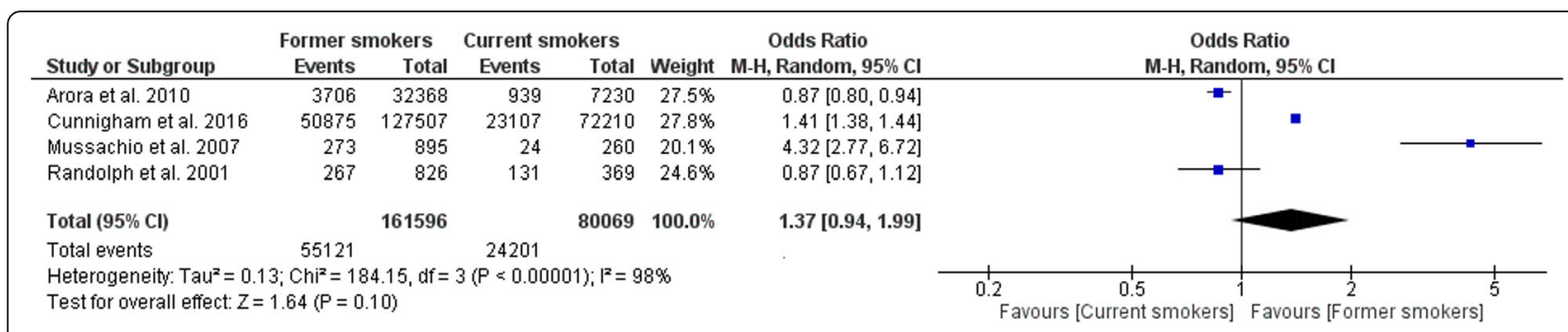

Fig. 2 Forest plot for meta-analysis of being edentulous in former smokers compared to never-smokers in cross-sectional studies ( $n=04$ studies, association measure: Odds ratio)

smokers $[21,22,40]$, the inclusion of recent quitters in the analysis could have reduced the effect size of smoking cessation on tooth loss in the cross-sectional studies.

Even though our meta-estimates were derived from observational studies, which usually present high heterogeneity, the results provided from the analysis of this kind of studies can be considered similar to those of randomized trials [50]. Besides, heterogeneity was considered in our meta-analyses (random-effects models) and explored (subgroup and meta-regression analyses), contributing to an appropriate judgment about the findings and helping in identifying potential sources of heterogeneity. In addition, another point that should be emphasized is that the sample size in observational studies is frequently larger than that of clinical trials. Altogether, the studies included in this review enrolled 638,389 individuals $(567,491$ subjects from cross-sectional studies and 70,898 participants from longitudinal studies). Moreover, there are methodological difficulties in using tooth loss as an outcome in interventional studies. It would be necessary a very long follow-up time and a very large sample size to analyze this outcome.

Some methodological differences between the studies should be pointed out. For example, while some studies $[22,40]$ asked the time since smoking cessation at the baseline questionnaire, others [3, 21, 41-43] considered as former smokers the subjects that stopped smoking during the follow-up time. These methodological differences could have influenced the results since in the first case $[22,40]$ participants could have stopped smoking many years before tooth loss. Time since cessation was the variable that better explained the heterogeneity in meta-regression. However, the effect was not significant, which could be related to the small number of studies included in this analysis. Another important consideration that has to be pointed out is that all included studies were carried out in high-income countries. It is necessary to be carefully to extrapolate our results to low-middle-income countries because it is known that socio-economic differences have an important role in oral health status, tooth loss and smoking status. Wellconducted studies with these populations are necessary.

None of the studies have used an objective measure of smoking status (e.g. salivary levels of cotinine or levels of carbon monoxide exhaled). Self-reported smoking status has been associated with underestimated smoking prevalence [51]. Along with the same lines, self reported tooth loss may not be accurate. Although clinical examination is the best method to determinate tooth loss, some studies $[27,28,53,36,22,40-42]$ used self-report to determinate this outcome. This method could have been chosen because of the high number of participants or the long follow-up time (longitudinal studies). Another shortcoming in the included studies was that the reason of tooth loss was not considered. This information could help to better explain the relation between smoking and tooth loss.

Despite the methodological limitations of the included studies, the findings of this systematic review support a beneficial effect of smoking cessation on the risk of tooth loss. Considering the benefits of quitting tobacco for the general health, and that smoking cessation

\begin{tabular}{|c|c|c|c|c|c|c|c|}
\hline \multirow[b]{2}{*}{ Study or Subgroup } & \multicolumn{2}{|c|}{ Former smokers } & \multicolumn{2}{|c|}{ Current smokers } & \multirow[b]{2}{*}{ Weight } & \multirow{2}{*}{$\begin{array}{l}\text { Odds Ratio } \\
\text { M-H, Fixed, } 95 \% \mathrm{Cl}\end{array}$} & \multirow{2}{*}{$\begin{array}{c}\text { Odds Ratio } \\
\text { M-H, Fixed, } 95 \% \mathrm{Cl}\end{array}$} \\
\hline & Events & Total & Events & Total & & & \\
\hline Mai et al. 2013 & 392 & 473 & 32 & 40 & $6.5 \%$ & $1.21[0.54,2.72]$ & \\
\hline Ojima et al. 2007 & 18 & 78 & 158 & 389 & $26.1 \%$ & $0.44[0.25,0.77]$ & \\
\hline Randolph et al. 2001 & 598 & 868 & 240 & 369 & $67.4 \%$ & $1.19[0.92,1.54]$ & \\
\hline Total $(95 \% \mathrm{Cl})$ & & 1419 & & 798 & $100.0 \%$ & $1.00[0.80,1.24]$ & \\
\hline \multirow{2}{*}{\multicolumn{7}{|c|}{$\begin{array}{l}\text { Total events } \quad 1008 \quad 430 \\
\text { Heterogeneity: Chi }{ }^{2}=10.18, d f=2(P=0.006) ; I^{z}=80 \% \\
\text { Test for overall effect: } Z=0.04(P=0.97)\end{array}$}} & \\
\hline & & & & & & & $\begin{array}{ccccc}1 & 1 & 1 & 1 \\
0.2 & 0.5 & 1 & 2 & 5 \\
\text { Favours [Current smokers] } & \text { Favours [Former smokers] }\end{array}$ \\
\hline
\end{tabular}




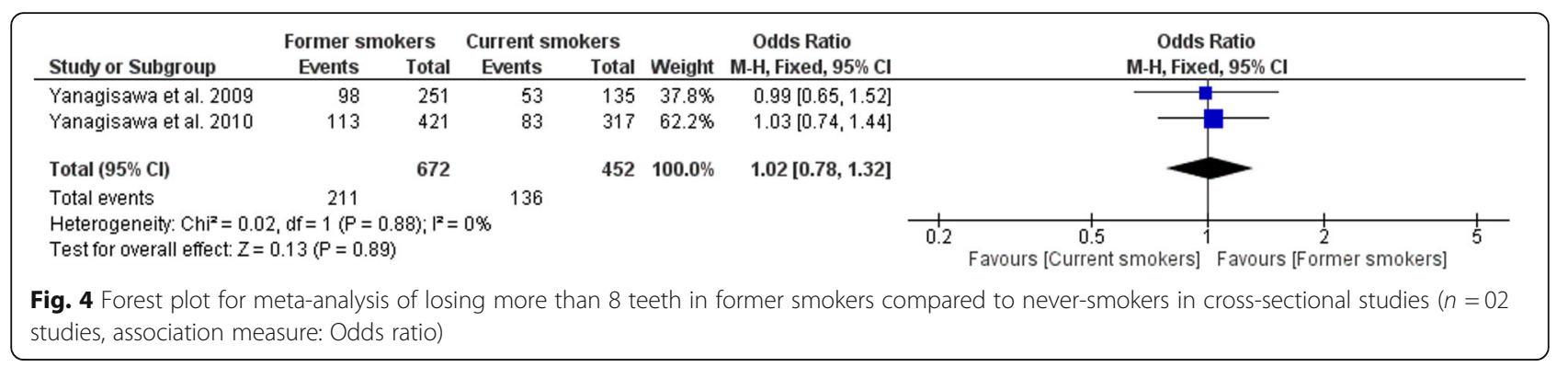

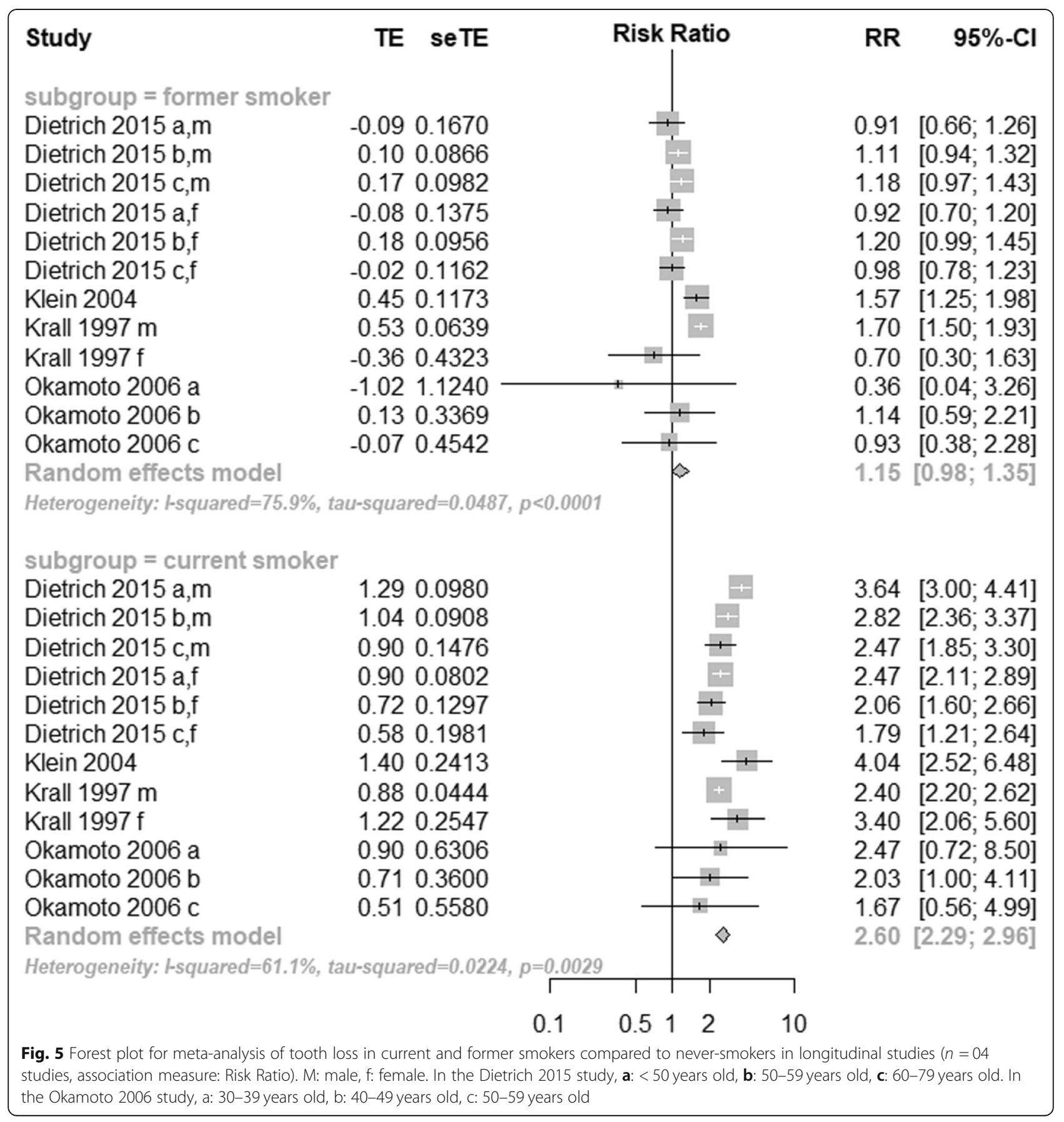


Table 5 Meta-regression analysis for the association between moderators and tooth loss

\begin{tabular}{|c|c|c|c|c|c|c|c|c|}
\hline \multirow[b]{2}{*}{ Moderator } & \multicolumn{4}{|l|}{ Former Smokers } & \multicolumn{4}{|l|}{ Current smokers } \\
\hline & Estimate* $(95 \% \mathrm{Cl})$ & $p$-value & Residual 12 & R2 & Estimate* $(95 \% \mathrm{Cl})$ & p-value & Residual 12 & R2 \\
\hline Age & 0.01 (-0.87 to 0.38$)$ & 0.30 & $0 \%$ & $0 \%$ & $-0.01(-0.03$ to 0.005$)$ & 0.15 & $77.6 \%$ & $0 \%$ \\
\hline Cigarretes & $-0.01(-0.10$ to 0.07$)$ & 0.76 & $0 \%$ & $0 \%$ & $-0.04(-0.14$ to 0.06$)$ & 0.43 & $64.7 \%$ & $0 \%$ \\
\hline Dropout ratet & $0.01(-0.01$ to 0.02$)$ & 0.50 & $74.1 \%$ & $0 \%$ & 0.004 (-0.01 to 0.02$)$ & 0.58 & $70.2 \%$ & $43.7 \%$ \\
\hline Time since cessation & $0.09(-0.01$ to 0.18$)$ & 0.06 & $22.0 \%$ & $57.8 \%$ & - & - & - & - \\
\hline
\end{tabular}

Cl: Confidence Interval, 12: residual heterogeneity / unaccounted variability, R2: amount of heterogeneity accounted for each variable, ${ }^{*}$ Coefficient of Linear Regression (meta-regression), + dropout rates considering the entire sample included in the study (or the any subgroup, when available)

interventions conducted by oral health professionals are effective [52], the dental setting seems to be appropriate to implement smoking cessation therapy.

\section{Conclusions}

This systematic review indicates that risk for tooth loss in former smokers is comparable to that of never smokers. Moreover, current smokers present a higher risk of tooth loss than former smokers.

\section{Supplementary information}

Supplementary information accompanies this paper at https://doi.org/10. 1186/s12903-019-0930-2.

Additional file 1. Funnel plots of longitudinal studies investigating the effect of smoking and smoking cessation on tooth loss. (a) former smokers vs. never smokers (Egger's test for asymmetry, $p=0.06)$, (b) current smokers vs. never smokers (Egger's test for asymmetry, $p=0.79$ ).

\section{Abbreviations}

Cl: confidence interval; MOOSE: Meta-analysis of Observational Studies in Epidemiology; NOS: Newcastle-Ottawa scale; OR: odds ratio;

PRISMA: Preferred reporting items for systematic reviews and meta-analyses; PROSPERO: International Prospective Register of Systematic Reviews; RR: risk ratio

\section{Acknowledgements}

None.

\begin{abstract}
Authors' contributions
MLSS: selected the papers, performed the papers validity assessment, elaborated tables and flow-chart, wrote the manuscript and submitted the manuscript; ESR: selected the papers, performed the papers validity assessment, performed meta-analysis of cross-sectional studies and contributed to write the manuscript; CCV: elaborated tables and contributed to write the manuscript; MMBF: performed the meta-analysis of longitudinal studies and contributed to write the manuscript; CMP: elaborated the search strategy, was consulted in case of discussion between the examiners of the validity assessment, contributed to write the paper and revised tables, figures and the final version of the manuscript. All authors read and approved the final version of the manuscript.
\end{abstract}

\section{Funding}

This study was partially financed by the Coordenação de Aperfeiçoamento Pessoal de Nível Superior - Brasil (CAPES) - Finance Code 001. Capes has promoted pos-graduation scholarship for the author Maria Luisa Souto.

\section{Availability of data and materials}

All data generated or analyzed during this study are included within the article (and its additional files).
Ethics approval and consent to participate

Not applicable.

Consent for publication

Not applicable.

\section{Competing interests}

Claudio Mendes Pannuti is one of the editorial board members for BMC Oral Health.

\section{Author details}

${ }^{1}$ Division of Periodontics, University of São Paulo, School of Dentistry, Av. Prof. Lineu Prestes, 2227, São Paulo, SP 05508-000, Brazil. ²Department of Dentistry, Periodontics Research Division, University of Taubaté, Taubaté, São Paulo, Brazil. ${ }^{3}$ Division of Pediatric Dentistry, University of São Paulo, School of Dentistry, São Paulo, Brazil.

Received: 19 February 2019 Accepted: 16 October 2019

Published online: 12 November 2019

\section{References}

1. Norderyd O, Hugoson A, Grusovin G. Risk of severe periodontal disease in a Swedish adult population. A longitudinal study. J Clin Periodontol. 1999 Sep;26(9):608-15.

2. Tomar SL, Asma S. Smoking-attributable periodontitis in the United States: findings from NHANES III. National Health and nutrition examination survey. J Periodontol. 2000 May:71(5):743-51.

3. Jansson L, Lavstedt S. Influence of smoking on marginal bone loss and tooth loss- a prospective study over 20 years. J Clin Periodontol. 2002 Aug; 29(8):750-6.

4. Bergström J, Eliasson S, Dock J. A 10-year prospective study of tobacco smoking and periodontal health. J Periodontol. 2000 Aug;71(8):1338-47.

5. Ramseier CA, Anerud A, Dulac M, Lulic M, Cullinan MP, Seymour GJ, Faddy MJ, Bürgin W, Schätzle M, Lang NP. Natural history of periodontitis: disease progression and tooth loss over 40 years. J Clin Periodontol. 2017 Dec; 44(12):1182-91.

6. Susin C, Oppermann RV, Haugejorden O, Albandar JM. Periodontal attachment loss attributable to cigarette smoking in an urban Brazilian population. J Clin Periodontol. 2004 Nov;31(11):951-8.

7. Corraini P, Baelum V, Pannuti CM, Pustiglioni AN, Romito GA, Pustiglioni FE. Risk indicators for increased probing depth in an isolated population in Brazil. J Periodontol. 2008;79(9):1726-34.

8. Preshaw PM, Heasman L, Stacey F, Steen N, McCracken Gl, Heasman PA. The effect of quitting smoking on chronic periodontitis. J Clin Periodontol. 2005; 32(8):869-79.

9. Rosa EF, Corraini P, de Carvalho VF, Inoue G, Gomes EF, Lotufo JP, De Micheli G, Pannuti CM. A prospective 12-month study of the effect of smoking cessation on periodontal clinical parameters. J Clin Periodontol. 2011 Jun;38(6):562-71

10. Chambrone L, Preshaw PM, Rosa EF, Heasman PA, Romito GA, Pannuti CM, Tu YK. Effects of smoking cessation on the outcomes of non-surgical periodontal therapy: a systematic review and individual patient data metaanalysis. J Clin Periodontol. 2013 Jun;40(6):607-15.

11. Rosa EF, Corraini P, Inoue G, Gomes EF, Guglielmetti MR, Sanda SR, et al. Effect of smoking cessation on non-surgical periodontal therapy: results after 24 months. J Clin Periodontol. 2014 Dec;41(12):1145-53. 
12. Leite FRM, Nascimento GG, Baake S, Pedersen LD, Scheutz F, López R. Impact of smoking cessation on periodontitis: a systematic review and meta-analysis of prospective longitudinal observational and interventional studies. Nicotine Tob Res. 2018 Jul 13. https://doi.org/10.1093/ntr/nty147.

13. Hung HC, Colditz G, Joshipura KJ. The association between tooth loss and the self-reported intake of selected CVD-related nutrients and foods among US women. Community Dent Oral Epidemiol. 2005 Jun;33(3):167-73.

14. Steele JG, Sanders AE, Slade GD, Allen PF, Lahti S, Nuttall N, Spencer AJ. How do age and tooth loss affect oral health impacts and quality of life? A study comparing two national samples. Community Dent Oral Epidemiol. 2004 Apr;32(2):107-14.

15. Cunha-Cruz J, Hujoel PP, Kressin NR. Oral health-related quality of life of periodontal patients. J Periodontal Res. 2007:42(2):169-76.

16. Tan H, Peres KG, Peres MA. Retention of teeth and Oral health-related quality of life. J Dent Res 2016;95(12):1350-1357. https://doi.org/10.1177/ 0022034516657992. Epub 2016 Jul 28

17. Hanioka T, Ojima M, Tanaka K, Matsuo K, Sato F, Tanaka H. Causal assessment of smoking and tooth loss: a systematic review of observational studies. BMC Public Health. 2011 Apr 8;11:221.

18. Sato F, Sawamura M, Ojima M, Tanaka K, Hanioka T, Tanaka H, Matsuo K. Smoking increases risk of tooth loss: a meta-analysisof the literature. World J Meta-Anal. 2013;1(1):16-26.

19. Albandar JM, Streckfus CF, Adesanya MR, Winn DM. Cigar, pipe, and cigarette smoking as risk factors for periodontal disease and tooth loss. $J$ Periodontol. 2000 Dec;71(12):1874-81.

20. Yanagisawa T, Marugame T, Ohara S, Inoue M, Tsugane S, Kawaguchi Y. Relationship of smoking and smoking cessation with number of teeth present: JPHC Oral health study*. Oral Dis. 2009 Jan;15(1):69-75.

21. Krall EA, Dietrich T, Nunn ME, Garcia RI. Risk of tooth loss after cigarette smoking cessation. Prev Chronic Dis. 2006 Oct;3(4):A115.

22. Dietrich T, Maserejian NN, Joshipura K, Krall EA, Garcia RI. Tobacco use and incidence of tooth loss among US male health professionals. J Dent Res. 2007 Apr;86(4):373-7.

23. Moher D, Liberati A, Tetzlaff J. Altman DG; PRISMA Group. Preferred reporting items for systematic reviews and meta-analyses: the PRISMA statement. PLoS Med. 2009 Jul 21;6(7):e1000097.

24. Stroup DF, Berlin JA, Morton SC, et al. Meta-analysis of observational studies in epidemiology: a proposal for reporting. Meta-analysis of observational studies in epidemiology (MOOSE) group. JAMA. 2000;283(15):2008-12.

25. Wells GA, Shea B, O'Connell D, et al. The Newcastle-Ottawa scale (NOS) for assessing the quality of nonrandomised studies in metaanalyses. 2001. Available from: http://www.ohri.ca/programs/clinical_epidemiology/oxford. asp. Accessed 12 Apr 2018.

26. Modesti PA, Reboldi G, Cappuccio FP, Agyemang C, Remuzzi G, Rapi S, Perruolo E, Parati G. ESH Working Group on CV Risk in Low Resource Settings. Panethnic Differences in Blood Pressure in Europe: A Systematic Review and Meta-Analysis. PLoS One. 2016 Jan 25;11(1):e0147601.

27. Arora M, Schwarz E, Sivaneswaran S, Banks E. Cigarette smoking and tooth loss in a cohort of older Australians: the 45 and up study. J Am Dent Assoc. 2010 Oct;141(10):1242-9.

28. Cunningham TJ, Eke PI, Ford ES, Agaku IT, Wheaton AG, Croft JB. Cigarette smoking, tooth loss, and chronic obstructive pulmonary disease: findings from the behavioral risk factor surveillance system. J Periodontol. 2016 Apr;87(4):385-94.

29. Hanioka T, Ojima M, Tanaka K, Aoyama H. Relationship between smoking status and tooth loss: findings from national databases in Japan. J Epidemiol. 2007 Jul;17(4):125-32.

30. Iwasaki M, Borgnakke WS, Ogawa H, Yamaga T, Sato M, Minagawa K, Ansai T, Yoshihara A, Miyazaki H. Effect of lifestyle on 6-year periodontitis incidence or progression and tooth loss in older adults. J Clin Periodontol. 2018 May; 15.

31. Mai X, Wactawski-Wende J, Hovey KM, LaMonte MJ, Chen C, Tezal M, Genco RJ. Associations between smoking and tooth loss according to the reason for tooth loss: the Buffalo OsteoPerio study. J Am Dent Assoc. 2013 Mar; 144(3):252-65.

32. Mundt T, Schwahn C, Mack F, Polzer I, Samietz S, Kocher T, Biffar R. Risk indicators for missing teeth in working-age Pomeranians--an evaluation of high-risk populations. J Public Health Dent. 2007 Fall;67(4):243-9.

33. Musacchio E, Perissinotto $E$, Binotto $P$, Sartori L, Silva-Netto F, Zambon $S$, Manzato E, Corti MC, Baggio G, Crepaldi G. Tooth loss in the elderly and its association with nutritional status, socio-economic and lifestyle factors. Acta Odontol Scand. 2007 Apr;65(2):78-86.
34. Ojima M, Hanioka T, Tanaka K, Aoyama H. Cigarette smoking and tooth loss experience among young adults: a national record linkage study. BMC Public Health. 2007 Nov 2;7:313.

35. Randolph WM, Ostir GV, Markides KS. Prevalence of tooth loss and dental service use in older Mexican Americans. J Am Geriatr Soc. 2001 May;49(5):585-9.

36. Similä T, Auvinen J, Timonen M, Virtanen Jl. Long-term effects of smoking on tooth loss after cessation among middle-aged Finnish adults: the northern Finland birth cohort 1966 study. BMC Public Health. 2016 Aug 24; 16(1):867.

37. Torrungruang K, Gongsakdi V, Laohaviraphab L, Likittanasombat K, Ratanachaiwong W. Association between cigarette smoking and the intraoral distribution of periodontal disease in Thai men over 50 years of age. J Investig Clin Dent. 2012 May;3(2):135-41.

38. Yanagisawa T, Ueno M, Shinada K, Ohara S, Wright FA, Kawaguchi Y. Relationship of smoking and smoking cessation with oral health status in Japanese men. J Periodontal Res. 2010 Apr;45(2):277-83.

39. Yoshida Y, Hatanaka Y, Imaki M, Ogawa Y, Miyatani S, Tanada S. Epidemiological study on improving the QOL and oral conditions of the aged--part 2: relationship between tooth loss and lifestyle factors for adults men. J Physiol Anthropol Appl Hum Sci. 2001 Nov;20(6):369-73.

40. Dietrich T, Walter C, Oluwagbemigun K, Bergmann M, Pischon T, Pischon N, Boeing H. Smoking, smoking cessation, and risk of tooth loss: the EPICPotsdam study. J Dent Res. 2015 Oct;94(10):1369-75.

41. Klein BE, Klein R, Knudtson MD. Life-style correlates of tooth loss in an adult Midwestern population. J Public Health Dent. 2004 Summer;64(3):145-50.

42. Krall EA, Dawson-Hughes B, Garvey AJ, Garcia RI. Smoking, smoking cessation, and tooth loss. J Dent Res. 1997 Oct;76(10):1653-9.

43. Okamoto $Y$, Tsuboi S, Suzuki S, Nakagaki H, Ogura Y, Maeda K, Tokudome S. Effects of smoking and drinking habits on the incidence of periodontal disease and tooth loss among Japanese males: a 4-yr longitudinal study. J Periodontal Res. 2006 Dec;41(6):560-6.

44. Åstrøm AN, Gülcan F, Ekbäck G, Ordell S. Long-term healthy lifestyle patterns and tooth loss studied in a Swedish cohort of middle-aged and older people. Int J Dent Hyg. 2015;13(4):292-300.

45. Do GL, Spencer AJ, Roberts-Thomson K, Ha HD. Smoking as a risk indicator for periodontal disease in the middle-aged Vietnamese population. Community Dent Oral Epidemiol. 2003;31(6):437-46.

46. Do LG, Slade GD, Roberts-Thomson KF, Sanders AE. Smoking-attributable periodontal disease in the Australian adult population. J Clin Periodontol. 2008;35(5):398-404.

47. Jawzali J. Association between salivary sialic acid and periodontal health status among smokers. Saudi Dent J. 2016;28(3):124-35.

48. Similä T, Virtanen Jl. Association between smoking intensity and duration and tooth loss among Finnish middle-aged adults: the northern Finland birth cohort 1966 project. BMC Public Health. 2015;15:1141

49. Tanaka K, Miyake Y, Sasaki S, Ohya Y, Miyamoto S, Matsunaga I, Yoshida T, Hirota Y. Oda H; Osaka maternal and child health study group. Active and passive smoking and tooth loss in Japanese women: baseline data from the Osaka maternal and child health study. Ann Epidemiol. 2005;15(5):358-64.

50. Anglemyer A, Horvath HT, Bero L. Healthcare outcomes assessed with observational study designs compared with those assessed in randomized trials. Cochrane Database Syst Rev. 2014;4:MR000034.

51. Wong SL, Shields M, Leatherdale S, Malaison E, Hammond D. Assessment of validity of self-reported smoking status. Health Rep. 2012;23(1):47-53.

52. Carr $A B$, Ebbert J. Interventions for tobacco cessation in the dental setting. Cochrane Database Syst Rev. 2012;6:CD005084.

\section{Publisher's Note}

Springer Nature remains neutral with regard to jurisdictional claims in published maps and institutional affiliations. 